\title{
Determinants of Economic Stability through Female Unemployment: Evidence from Pakistan
}

\author{
Malik Shahzad Shabbir * Aniqa Zeb ${ }^{\dagger}$
}

\begin{abstract}
The objective of this study is to capture a nexus between economic stability and female unemployment in Pakistan. Since economic stability enables macro-economic objectives such as sustainable growth, it creates conductive environment for employment. This study used foreign direct investment (FDI), consumer price index (CPI), fiscal deficit, debt to GDP, interest rate and exchange rate regarded as indicators of economic stability. Whereas, time series data for the period from 1973 to 2015 has employed through Augmented Dickey Fuller and Phillip-Perron and unit roots tests are applied to check the stationarity of the data. It has found that data is a mix of level I(0) and 1st difference I(1), which further justify us to apply auto regressor distributed lags (ARDL) bound testing approach for results. The Error Correction Mechanism (ECM) technique has applied for the short run dynamics of the models. However, CPI has positive and significant relationship with female unemployment in Pakistan. Whereas, exchange rate has negative related with female unemployment. Moreover, it is highly recommended to maintain economic stability through monetary and fiscal policy mechanism and there is also a dire need to formulate gender sensitive policies to create more employment opportunities to female labour force in the economy.
\end{abstract}

Keywords: Economic stability, female unemployment, sustainable growth, ARDL.

\section{Introduction}

Economic stability enables the particular objective such as sustainable growth to be achieved, which will create an environment for employment through healthy business activity. It also guarantees certainty and confidence of the investor, which will develop human resource and invest in sophisticated technology sector. Economic stability prevents economic and financial crises, fluctuations in economic activities, high inflation and excessive volatility in exchange rate, because instability increases uncertainty, avert investment, and hinders economic growth. Furthermore, economic stability buffers an economy from external shocks prepare it for growth through a policy prescription. Moreover, currency fluctuations in domestic currency, larger debt and deficits and persistent increase in prices decelerates the process of growth. According to Maastricht Criteria stability is measured by five variables for instance, low and stable inflation, persistent low interest rate, lower national debt relative to GDP, fiscal deficits and currency stability.

On the other hand, unemployment exerts multidimensional impact on an economy

\footnotetext{
*University of Lahore. E-mail: mshahzad786.pk11@gmail.com

${ }^{\dagger}$ University of Karachi.
} 
such as, social, political and economic impacts. Unemployment arises due to deteriorating economic and social displays such as weak law and order condition, uncertain government policies towards development, lack of policy continuation and investment etc. The economic and social cost of unemployment is very high. It increases poverty, erosion of human skills, stigma, social exclusion and social and economic unrest. Moreover, it also adds social and economic inequality in the masses and most importantly increases poverty. The government of Pakistan also faces significant decline in revenues in the form of direct and indirect taxes as the taxpayers shrink down. On the other side, developing countries are experiencing rapid growth in population, which threats the governments to create opportunities in the job market. The Pakistan economy is also a developing phase and lags behind in various economic and social aspects.

According to the Labour Force Survey (2015-16), revealed that Pakistan has 61.04 million labour forces. The employed population is 56.01 million, while rest of 3.73 million people are unemployed. From last couple of years, Pakistan is experiencing a significant transition from agriculture sector to industrial and services sectors. The labour force employed in agriculture sector is $24.27 \%$ in the year $2014-15$ as compared to 24.57 in year 2013-14. The rural unemployment has increased to $5.5 \%$ in 2014-15 as compared to 5.1 $\%$ in 2013-14. However, urban unemployment remained stable to $8.8 \%$ for the last few years. Another very significant cause of unemployment is law and order situation in the country, which hinders the flow of domestic and foreign investment. The real state sector becomes also one of the major sectors in the economy; a large component of the real sector output comes from agriculture. A core reason of unemployment is lack of economic stability. However, economic stability portrays an economy that has minimized exposure to external shocks, which in turn boost its prospects for prolonged growth.

The Pakistan is considered the 10th largest country according to the size of the labor force in the world. According to the Economic Survey of Pakistan (2014-2015) revealed that potential labor force has increased to 61 million as compared to 59.7 million in 2012-2013. The statistics confirmed the addition of 1.3 million people to the labor force. Additionally, during this period, employed population increased to 57.4 million from 56 million. This implies that 1.4 million get employed. However, number of unemployed people fallen to 3.60 million from 3.73 for the same period.

However, female unemployment rate is $10.54 \%$ of the total female labor force which is the highest unemployment rate as compared to other South Asian countries such as, India 3.81\%, Bangladesh $4.73 \%$ and Sri Lanka 8.5\%. Moreover, female labor force participation rate of the country is the lowest in the region which is $22 \%$ as compared $43 \%$ in Bangladesh, 30\% in Sri Lanka and 26\% in India. Increasing FLS can play a key role in increasing economic prosperity of the country. There is a dire need to create more employment opportunities for female work force to increase their participation rate in economic activities.

In our country, women are restricted to live inside the houses, which results into an increased burden on the male family members. In other words, females are not allowed to participate in the formal sectors resulting in a burden to be borne by the economy in the form of large dependent population. If we bring them in the formal sectors, it will drive the economy on the road to growth and progress because when every one 
of the working age without any gender biasness will work, that will definitely promote prosperity, growth, harmony and equality in the economy.

\section{Motivation of the Study}

Unemployment is an economic and social disgrace for male and female work force. Since, female workers are few in the job market and dwindling economic condition adds fuel to the fire. Moreover, the female jobs dependent upon stable economic conditions of the country. Furthermore, the unemployment of females reduces their purchasing power and empowerment along with the increase in gender inequality. In the world, women are slightly more than men and the half of the population is out of jobs, this figure augments gender inequality, less empowerment and a low standard of living. In this scenario, healthy growth, peace, stability and equality are just a dream only.

This study is the first to undertake the economic stability and its impact on female unemployment in the context of Pakistan. However, taking female unemployment and social indicators; but we are investigating determinants of female unemployment through macro economic variables. This research is part of a project which includes total unemployment male unemployment and this paper. Furthermore, this issue demands attention from researcher to highlight it and put the actual position of female unemployment in front of policy makers to design their policies according to the given statistics values. The distribution of paper is as; subsequent chapter is the review of existing literature, followed by methodology, results and discussion, conclusion \& policy recommendations and finally references.

\section{Literature Review}

The literature review is divided in to two sections; empirical literature on total unemployment and second female specific unemployment and macroeconomic indicators.

\section{Empirical Literature on Total Unemployment}

Lyndon and Lucky (2016) conducted the study in the context of Nigeria in order to find the effect of money supply, exchange rate, government expenditure and public debt on unemployment. However, multiple regression technique has been adopted by employing data over the period 1985 to 2014. It has been found that macroeconomic tools like government expenditures; money supply and public debt have positive effect on unemployment and the exchange rate increases unemployment ratio.

Stephen, Olugbenga, Yusuf, and Adebayo (2015) applied Engle Granger co-integration technique to find the long run dynamics between unemployment and national output. They used the data from the period 1980 to 2011 to find the results for Nigeria. The rest of other variables of the study are total factor productivity, net investment or private domestic investment (PDI). The overall results show that both variables are insignificantly related to each other. 
Heid and Larch (2014) centered twenty eight (28) Organizations for Economic Cooperation and Development (OECD) countries to capture a qualitative framework of international trade and unemployment. The variables of the study are trade, employment, output and distance of the trading countries. They worked on PTA's of OECD with US from 1950 to 2006 and found that countries experienced less increase in GDP have negative employment effect. Zeb, Qiang, and Sharif (2014) utilized data for Pakistan economy from 1995 to 2011 to analyze the impact of foreign direct investment by running multiple regressions. The other variables employed in the study are FDI, corruption, population size and inflation. It has been successfully obtained that investments play a vital role in the reduction of unemployment in Pakistan.

Ahmad, Yasmeen, and Ahmad (2013) obtained data for unemployment, inflation, trade and exchange rate for Pakistan from 1984 to 2012. After applying OLS technique, Phillips curve has been found in Pakistan's economy. Hussain, Siddiqi, and Iqbal (2010) found a negative association of unemployment with economic progress in the country. The results are obtained by employing data from the period 1972 to 2006. The variables of the interest were economic growth, unemployment, trade openness, capital and labor, poverty and human capital.

Mahmood, Bokhari, and Aslam (2013) pragmatic Johansen maximum likelihood cointegration and Granger Causality technique employed for the data from 1975 to 2007. The purpose of this study is to investigate the crime, poverty, inflation and unemployment. The results revealed that unemployment, poverty and inflation cause crimes. There is also long run involvement between unemployment, inflation, crime and poverty.The effect of exchange rate on unemployment in the context of ASIAN countries by running different regression equations using data from 1995 to 2005 is checked. They found that exchange rate volatility positively affects the unemployment rate.

Saeed (2002) used various economic variables like imports, exports, imports taxes, FDI and economic growth to find impact of these variables on unemployment and poverty.She has taken post integration data of the country from 1988 to 2001 . The results found that trade openness leads to deteriorations in balance of payment and persistent increase in poverty and unemployment.

\section{Female Unemployment and Macroeconomic Indicators}

Elborgh-Woytek et al. (2013) has reviewed different studies and concluded that women participation in the formal sector have fruitful outcomes not only for themselves but also for the economy as well. It has multi-dimensional impact on economy. Feldmann (2013) has captured the impact of interest on labor market performance in a number of countries. Through this panel study, he has found that interest rate has high correlation with unemployment rate of females. Begum Sadaquat and Sheikh (2011) discussed the factors that create difficulties for women to get employed. These factors include religious, cultural, traditional impediments. This research has found that female unemployment is due to less education.

Braunstein and Seguino (2018) have undertaken thirteen (13) Latin American economies to capture the impact of economic policy and gender inequality in employment from the 
period 1990-2010. It has found in the study that social spending increase employment for female, public investment is also positively related to the employment and lastly, terms of trade also benefit women in the labor market. The real exchange rate has found to stimulate the female unemployment ratio.

Berument, Dogan, and Tansel (2006) used VAR techniques and employed quarterly data for the period 1980:1 to 2003:4 in the context of Turkey. The variables in their study were real GDP, price, exchange rate, inter-bank interest rate and unemployment rate (total and male and female). They have found that female unemployment increases with innovations in interest rate, inter-bank interest rate in the short run deteriorate female unemployment. However, there is no specific study in the context of Pakistan country that has taken the female unemployment to find out the impact of economic stability. Hence, our study is going to fill the gap by capturing a nexus between female unemployment and economic stability in Pakistan.

\section{Methodology}

The estimation strategy starts from the unit root test. Although, numerous research studies are available that applied ordinary least square (OLS) technique for the estimation of time series data. The Johnson co-integration technique is also another famous econometric technique for time series data. However, there are some limitations using these techniques. The anonymity in using OLS is that it assumes residual term as normally distributed with zero mean and finite constant (Shabbir \& Rehman, 2016). If variables are not integrated of I (0) or stationary, ordinary least square presents indistinct output, which is definitely not helpful in analysis. On the other hand, Johnson co-integration method requires a large number of observations. Secondly, for truthful results, variables must be integrated if I (1) on stationary level at first difference. Hence, we applied Auto regressive distributed lag model (ARDL), which provide accurate results of the estimation even with small number of observations. Subsequently, it undertakes data, which is implying a mix of I (0) and I (1), that it is not necessary for the variables to be integrated of the same order.

In our study, we worked with two methods of unit root test for the stationarity of the data, Augmented Dickey- Fuller test, which is developed by David Dickey and Wayne Fuller in 1981 and Phillips.Perron test, which is developed by Peter Phillips and Pierre Perron in 1988. The advantages of the ARDL method, it measures accurately the long-run parameter estimates become efficient and the estimated standard errors are unbiased. It is also a fact that most of the ARDL parameters can be estimated freely for instance, to guarantee a positive association between dependent and explanatory variables, 0 must be positive however, 1 might be freely estimated providing B1+B2 is greater than zero.

\section{Unit Roots Test}

The time series data demonstrate trend over the time. In literature, we have found two methods to remove or de-trend the time series, first method is 1st differencing and second 
method is time trend regression. The Unit root test is applied to find out whether the data is stationary or non-stationary.

\section{ARDL Bounds Testing Approach}

ARDL stands for autoregressive -Distributed Lag. This type of regression had used for decades. However, in recent time this test shows a valuable technique for examining the presence of long run association among economic time series. In its basic form ARDL model look like as below.

$$
Y_{t}=\beta_{o}+\beta_{1} Y_{t-1}+\ldots . \beta_{k} Y_{t-p}+\alpha_{o} X_{t}+\alpha_{1} X_{t-1} \ldots+\alpha_{q} X_{t-q}+\epsilon_{t}
$$

Where, $\epsilon_{t}$ it is a random error term. The model is autoregressive; the dependent variable is explained by lagged value of itself and successive lag of the explanatory variable because of lagged values of dependent variable as regressor. The OLS estimation of ARDL model will give biased coefficient estimation, furthermore if error term is auto correlated then OLS will be again inconsistent estimator.

\section{Modeling Framework}

This study examines the effect of economic stability on female unemployment, although unemployment is one of necessary variables for economic stability, however, it is also a social issue that affects economy as well as welfare of the unemployed population in the country.

$$
\text { F.un }=f(C P I, \text { Ex.debt, ir, exrate, fiscal deficit, FDI })
$$

Where, F.un $=$ female rate of unemployment, $\mathrm{CPI}=$ Consumer Price Index (inflation prevailing in the economy), Ex. debt = external debt to GDP (debt/GDP), ir = interest rate, Ex rate $=$ exchange rate $(\$ / R s)$, Deficit $=$ fiscal deficit, FDI $=$ Foreign Direct Investment.

We have used data in proportion to GDP, for empirical analysis, we have to convert our equation into econometric form. The empirical equation of the model is as follow:

$$
F U N_{t}=\gamma_{0}+\gamma 1 I N F+\gamma 2 I R+\gamma 3 E X+\gamma 4 E X . D E B T+\gamma 5 D E F I C I T+\gamma 6 F D I+\epsilon_{t}
$$

Now the ARDL model of the estimated equations;

$$
\begin{gathered}
F U N_{t}=\beta_{o}+\beta_{1} U N F_{t-1}+\ldots . \beta_{k} F U N_{t-p}+\alpha_{O} F D_{t}+\alpha_{1} F D_{t-1}+\ldots .+\alpha_{q} F D_{t-q}+ \\
\delta_{o} C P I_{t}+\delta_{1} C P I_{t-1}+\ldots+\delta_{r} C P I_{t-r}+\gamma_{o} E X . R A T E_{t}+\gamma_{1} E X . R A T E_{t-1}+\ldots \\
\gamma_{s} E X . R A T E_{t-s}+\gamma_{o} F D I_{t}+\gamma_{1} F D I_{t-1}+\ldots . \gamma_{x} F D I_{t-x}+\lambda_{0} D E B T_{t}+ \\
\lambda_{1} E X . D E B T_{t-1}+\ldots . \lambda_{y} E X . D E B T_{t-y}+\phi_{0} I R_{t}+\phi_{1} I R_{t-1}+\ldots+\phi_{y} I R_{t-y}+\epsilon_{t}
\end{gathered}
$$

The unrestricted error correction model (UECM) of autoregressive-distributed lag model (ARDL) bounds testing is modeled as follows: 
However, $\triangle$ is difference operator and is used for trend variable and $\epsilon_{t}$ is stochastic term, which is assumed to be normally distributed with zero mean and fixed variance. Now we will calculate F-statistic of ARDL to inspect whether there is co-integration for instance, long run association among the variables exists or not. It is necessary to choose appropriate lag order because value of F-statistic varies with lag order (Shabbir \& Rehman, 2016). We use Akaike Information Criteria (AIC) to choose a suitable lag length for model. Moreover, F-test, developed by Pesaran, Shin, and Smith (2001) is applied to observe the joint significance of estimates of lagged level of the series.

The null hypothesis of no co-integration is

$$
H_{o}=\vartheta_{U N E M P}=\vartheta_{I N F}=\vartheta_{I R}=\vartheta_{E X}=\vartheta_{D E B T}=\vartheta_{\text {deficit }}=\vartheta_{F D I}=0
$$

The alternative hypothesis of co-integration is :

$$
H_{\alpha}=\vartheta_{U N E M P} \neq \vartheta_{I N F} \neq \vartheta_{I R} \neq \vartheta_{E X} \neq \vartheta_{D E B T} \neq \vartheta_{\text {deficit }} \neq \vartheta_{F D I} \neq 0
$$

Once, the long run relationship among the variables in the model has been established, it is necessary to find short run impact of economic stability on unemployment. For the purpose, we are applying Error Correction Mechanism (ECM). The empirical equation of ECM is modeled as follows;

$$
\begin{gathered}
\triangle F U N_{t}=\delta_{1}+\sum \delta_{U N F} \triangle U N F_{t-1}+\sum \delta_{F D I} F D I_{t-j}+\sum \delta_{C P I} C P I_{t-k} \\
+\sum \delta_{E X . R A T E} E X . R A T E_{t-l}+\sum \delta_{F D I} F D I_{t-m}+\sum \delta_{E X . D E B T} E X . D E B T_{t-o}+ \\
\sum \delta I R I R_{t-p}+\delta E C M_{t-1}+\epsilon_{t} \ldots .
\end{gathered}
$$

Where, $\vartheta$ is the estimate of lagged error term that captures the speed of adjustment from short run towards long run equilibrium path? We have also performed diagnostic tests to check the Classical Linear Regression Model (CLRM) assumptions, for example, normality of residual term, serial correlation, autoregressive conditional heteroscedasticity, white heteroscedasticity and specification of short run model. By using the cumulative sum (CUSUM) and the cumulative sum of squares (CUSUM sqs) reliability of short run estimations is examined, which is proposed by Pesaran et al. (2001).

The above methodology has explained due to the fact that data is not stationary and is a mix of I (0) and I (1). As the data is a mix of I (0) and I (1), it is necessary to employ ARDL method to obtain the empirical evidence from the models.

\section{Results and Discussion}

\section{Unit Root Results}

As discussed in the previous chapter that it is important to check for the stationarity of the time series data in order to avoid spurious results. The unit root test is used to de- 
trend the time series data before applying any econometric technique. The table 1 below describes the stationarity of the data.

Table 1

Unit Root Results

\begin{tabular}{lcccc}
\hline Variables & \multicolumn{2}{c}{ ADF Unit Root } & \multicolumn{2}{c}{ Phillips - Perron Unit Root } \\
\hline \multicolumn{4}{c}{ All variables are tested against 5\% confidence level } \\
\hline Level I (0) & 1st Difference I & Levels I (0) With intercept & 1st Difference I (1) \\
\hline Demale unemployment & -1.989 & $-7.185^{*}$ & -1.85 & $-7.792^{*}$ \\
Exchange rate & -1.972 & $-4.217^{*}$ & $-9.129^{*}$ & $-14.433^{*}$ \\
FDI & 1.796 & -0.363 & 2.63 & $-3.815^{*}$ \\
Interest rate & 0.735 & $-6.088^{*}$ & 0.786 & $-6.088^{*}$ \\
Budget deficit & $-3.688^{*}$ & $-7.041^{*}$ & $-3.765^{*}$ & $-9.965^{*}$ \\
CPI & $-3.408^{*}$ & $-8.193^{*}$ & $-3.374^{*}$ & $-8.644^{*}$ \\
\hline
\end{tabular}

The unit root test has been applied to check the stationarity of the data such as to detrend the data. For the purpose, we have applied ADF unit root and Phillip Perron (PP) test. In above table, we have applied with intercept. First, variables are tested at levels and then at 1st difference with intercept. The female unemployment is not stationary at levels in ADF and PP. It became stationary at 1st difference in both ADF and PP. The external debt is not stationary with intercept in ADF and PP, whereas debt is stationary at levels and 1st difference in PP and at 1st difference in ADF.The exchange rate is not stationary at levels and 1st difference in ADF, while it is stationary at the 1st difference in PP. The FDI is non-stationary as t-statistic at level is insignificant, when tested with intercept. However, it is stationary to significant at 1st difference with intercept in the context of both techniques.

The Interest rate is stationary at levels and 1st difference both at ADF and Phillip Perron test when tested with intercept. The budget deficit is stationary at levels and 1st difference both at ADF and PP. However, CPI is stationary at ADF at levels but non-stationary at 1st difference. But the variable is stationary at both i.e. levels and 1st difference at Phillip Perron. All the variables are tested against 5\%level of confidence. The regression Results of the model are as follows in table 2.

\begin{tabular}{lccc}
$\begin{array}{l}\text { Table } 2 \\
\text { Regression Results }\end{array}$ & \multicolumn{3}{l}{} \\
\hline Variables & Coefficient & T-Statistics & Prob. $^{*}$ \\
\hline Budget deficit (-4) & 4.042 & 2.161 & 0.096 \\
Debt (-1) & -80.35 & -2.155 & 0.097 \\
CPI & 2.324 & 2.921 & 0.043 \\
CPI (-3) & 2.553 & 2.221 & 0.091 \\
Exchange Rate (-4) & -3.988 & -2.493 & 0.067 \\
FDI (-2) & -1.690 & -3.037 & 0.038 \\
FDI (-3) & -3.234 & -2.455 & 0.070 \\
Constant & -72.22 & -1.845 & 0.138 \\
R-squared & 0.984 & Akaike info criterion & 3.998 \\
Adjusted R-squared & 0.855 & Schwarz criterion & 5.464 \\
Log likelihood & -41.97 & Durbin-Watson stats & 2.722 \\
F-statistic & 7.645 & Prob. (F-statistic) & 0.029 \\
\hline
\end{tabular}

First the regression has run to find the determinants of female unemployment in the 
context of the country. The goodness of fit test indicates that $85 \%$ variations in the model are explained by the variables encircled in the study. The Aikaike information criterion is chosen for the methodology as per its lower values than Schwarz criterion. The overall model is also significant as F-statistic is 7.64. When accumulated budget deficit increase the female become joblessness. Furthermore, budget deficit increases the pressure on government to bridge the gap between revenue and expenditures. The debt is found as a strong determinant for female job opportunities. Whereas, deficit financing of the government may slower the economy and it may have some room for the female workforce to stay in the job market. The reason could be the fact that females are employed in relatively small enterprises, which is not at once hurt by such phenomenon.

The result of CPI indicates that the current and in the lag year increase the job loss for women. Whereas, inflation is not only hurts consumer but also producer. It diminishes producers' profit which leads him for various harsh decisions such as higher prices of the products, wage cut and labor cut. However, this labor adds to the employed work force of the country. When exchange rate increases the devaluation of domestic currency brings fruitful outcomes in the shape of increased job opportunities in the market. This will increase the absorption capacity for the female workers in the job market. However, foreign investment is also a positive determinant of female employment. This female unemployment is reduced when foreign investment has injected into different sectors of the economy. These sectors will call for labor resulting job openness for female employees as well. Finally, the remaining variables (error term), which are not confined in the model are also positive determinant in reducing unemployment, these may include social as well as economic indicators.

\begin{tabular}{|c|c|c|}
\hline \multicolumn{3}{|c|}{ Null Hypothesis: No long-run relationships exist } \\
\hline Test Statistic & Value & K \\
\hline F-statistic & 5.78 & 6 \\
\hline Significance & $\mathrm{I}(0)$ Bound & I(1) Bound \\
\hline $10 \%$ & 2.12 & 3.23 \\
\hline $5 \%$ & 2.45 & 3.61 \\
\hline $2.50 \%$ & 2.75 & 3.99 \\
\hline $1 \%$ & 3.15 & 4.13 \\
\hline
\end{tabular}

The above table 3 shows that ARDL bound test is incomplete without knowing the bound test values before applying further techniques. It is a necessary condition that the F-statistic for bound test must be greater than the critical values of the I (0) and I (1) bounds. It is observed from the table above that the null has been rejected at all level of significance.

\section{Short Run Dynamics}

The short run dynamics of the model are described in table 4 . The budget deficit improves female unemployment such as reduction the female dependency in the economy. It has seen in above table that inflation in the short run increase women unemployment in the 
current period, while lagged CPI increase employment rate. The depreciation of domestic currency in the short run lumps the female joblessness, this may happen due to the reason for the short period, more work pressure on workers. The females cannot perform well in the pressure and sensitive situations, which may lead a negative sign in female employment ratio.

\begin{tabular}{lccc}
$\begin{array}{l}\text { Table } 4 \\
\text { Short Run Dynamics }\end{array}$ & & & \\
\hline Variables & Co-efficient & t-statistic & Prob. \\
\hline D (Budget deficit (-3)) & -4.042 & -2.161 & 0.097 \\
D(CPI) & 2.324 & 2.921 & 0.043 \\
D (CPI (-2)) & -2.553 & -2.221 & 0.091 \\
D (Exchange Rate (-3)) & 3.988 & 2.494 & 0.067 \\
D (FDI (-1)) & 1.69 & 3.037 & 0.038 \\
D (FDI (-2)) & 3.234 & 2.455 & 0.07 \\
CointEq (-1) & -1.484 & -2.768 & 0.05 \\
\hline
\end{tabular}

The foreign investment is also not helping female employment, which is due to the fact that the investment is made in infrastructure activities; it becomes profitable business in our country now-a-days. This economic and production activity does not need women to be a part of them, hence outcome of this activity is increased unemployment for females. However, the error correction term is negative and significant which implies that the model will converge towards long run equilibrium.

\section{Long Run Dynamics}

The long run dynamics has a pivotal importance in our study.Table 5 portrays long run results for the model.

\begin{tabular}{lccc}
$\begin{array}{l}\text { Table } 5 \\
\text { Long Run Co-efficients }\end{array}$ & & \\
\hline Variables & Co-efficient & T-Statistics & Prob. \\
\hline Budget deficit & 0.920 & 0.370 & 0.729 \\
Debt & 18.212 & 1.585 & 0.188 \\
CPI & 1.664 & 2.823 & 0.047 \\
Real Interest rate & -0.815 & -1.978 & 0.119 \\
Exchange rate & -2.531 & -2.271 & 0.085 \\
FDI & -5.654 & -4.508 & 0.011 \\
Constant & -38.833 & -1.564 & 0.193 \\
\hline
\end{tabular}

The above table indicates that budget deficit has no long run relationship with female unemployment. The reason may be mostly women are a part of the small and medium enterprises which are not directly hurt by the government intervention into the financial market. The external debt is also in line with the above variable that it does not determine female dependency rate. However, the inflation, in the long run is positively integrated with women unemployment, which implying that inflation increases the production cost of the producer. This forms the pressure on the producers, who minimize the labour employed and as female workers are already not in large percentage, this phenomenon make worse conditions for them. The exchange rate designates the form of depreciation 
of the domestic currency, which make our export cheaper resulting in exports demand and raises the demand for labour; as well as female labour force. Finally the FDI increases employment opportunities for women in the long run. As it has discussed earlier, that capital inflow in the form of FDI result in the development of different projects, which will definitely open the doors for women employment.

\section{Conclusion}

It is proved in this study that women are employed in informal sector of the economy but their employment role is also sensitive to economic stability. This study concludes with these remarks that inflation, in the long run is positively integrated with women unemployment, which implying that inflation increases the production cost of the producers. This forms the pressure on the producer who reduced the labour employed and as female workers are already not in a large percentage in the existing market.The exchange rate decreases the female unemployment in Pakistan. However, FDI increases the employment opportunities for women in the long run dynamics. As it has been discussed earlier, that capital inflow in the form of FDI results plays a positive role in the development of different projects which will open the doors for women employment.

The study is concluded with the policy implications and options provided to the concerned authorities if implemented properly can bring economic stability in Pakistan. It is also recommended that private sector should be encouraged to invest in human resources and encouraging work force to learn skills and start their own small businesses, because government alone cannot absorb the huge population of educated workforce.

This study leaves a comprehensive policy prescription as it contains empirical evidence of almost all major macro-economic indicators. Furthermore, the economic stability in whole refers to low and stable macroeconomic indicators, which eventually lead economic activity in the country. The policy recommendations are as follows:

- The gender sensitive policies are welcome and absorb female labour in the market should be made in order to boost the confidence of the female worker to work in the formal economy

- The employment quotas should be specified in the public and private sector to create employment opportunities for half of the country's population.

- The two major policies such as fiscal and monetary policy are extremely important for an efficient and productive economy. The monetary and fiscal policy mechanism assures the economic stability. Hence, there is a dire need to set tools of these policies in order to meet the objective of maintaining economic stability which eventually decreases unemployment.

- The concerned authorities should immediately implement policies to entice foreign capital. The attraction of these funds in the country will trigger the new capital inflows, which will not only increase the FDI but also boost the economic development and help in reducing unemployment. 


\section{References}

Ahmad, N., Yasmeen, K., \& Ahmad, A. (2013). Inflation and unemployment: Is the tradeoff dead or alive in Pakistan? Pensee Journal, 75(11), 482- 492.

Begum Sadaquat, M., \& Sheikh, Q.-t.-a. A. (2011). Employment situation of women in Pakistan. International Journal of Social Economics, 38(2), 98-113.

Berument, H., Dogan, N., \& Tansel, A. (2006). Economic performance and unemployment: Evidence from an emerging economy. International Journal of Manpower, 27(7), 604623.

Braunstein, E., \& Seguino, S. (2018). The impact of economic policy and structural change on gender employment inequality in Latin America, 1990-2010. Review of Keynesian Economics, 6(3), 307-332.

Elborgh-Woytek, M. K., Newiak, M. M., Kochhar, M. K., Fabrizio, M. S., Kpodar, M. K., Wingender, M. P., ... Schwartz, M. G. (2013). Women, work, and the economy: Macroeconomic gains from gender equity. International Monetary Fund.

Feldmann, H. (2013). Real interest rate and labor market performance around the world. Southern Economic Journal, 79(3), 659-679.

Heid, B., \& Larch, M. (2014). International trade and unemployment: A quantitative framework.

Hussain, T., Siddiqi, M., \& Iqbal, A. (2010). A coherent relationship between economic growth and unemployment: An empirical evidence from Pakistan.

Lyndon, M. E., \& Lucky, E. U. (2016). The effect of government expenditure and money supply on unemployment in Nigeria. International Journal of Management Studies.

Mahmood, Y., Bokhari, R., \& Aslam, M. (2013). Trade-off between inflation, interest and unemployment rate of Pakistan: A cointegration analysis. Pakistan Journal of Commerce and Social Sciences, 7(3), 482-492.

Pesaran, M. H., Shin, Y., \& Smith, R. J. (2001). Bounds testing approaches to the analysis of level relationships. Journal of applied econometrics, 16(3), 289-326.

Saeed, N. (2002). Impact of globalization on Pakistan's economy. Pakistan Institute of Development Economics.

Shabbir, M., \& Rehman, A. (2016). The impact of financial crises and economic growth of East Asian countries. The Journal of Internet Banking and Commerce, 21(1).

Stephen, A., Olugbenga, L., Yusuf, O., \& Adebayo, A. A. (2015). Impact of unemployment on national output in Nigeria, 1980-2011. Historical Research Letter, 25(2).

Zeb, N., Qiang, F., \& Sharif, M. (2014). Foreign direct investment and unemployment reduction in Pakistan. International Journal of Economics and Research, 5(2), 10-17. 